\title{
NARRATIVA DE LA VIOLENCIA Y TESTIMONIO DEL ‘DESTIERRO’ EN LOS CUENTOS DE EDUARDO ANTONIO PARRA
}

\author{
Ana María González Luna C. \\ Università degli Studi di Milano - Bicocca
}

Narrar lo que sucede para romper el silencio, para vencer el miedo, para no olvidar. Contar lo que es silenciado o invisibilizado en un sistema económico y político que conoce tan bien el poder del relato que produce el suyo propio. Crear historias para representar la violencia, para contrastar la versión oficial, para dar voz a los que se la han quitado, para iluminar los espacios oscurecidos. Regalar historias de lugares para hacerlos habitables. Esto es lo que Eduardo Antonio Parra hace con su narrativa.

Si bien nació en León, Guanajuato, el norte forma parte fundamental de su literatura. El norte es su espacio privilegiado, el que conoce, indaga, estudia y narra. Parra se identifica con sus contemporáneos Élmer Mendoza, Luis Humberto Crostwaite y Juan José Rodríguez en cuanto, sin haberlo programado, comparten la misma intención: «narrar el norte, narrar el sitio donde habíamos nacido y crecido» ${ }^{\perp}$. Un mundo complejo que no puede reducirse al tópico del narcotráfico, porque la literatura del norte no es solo narcoliteratura, como parecía indicar desde Ciudad de México el crítico Rafael Lemus al afirmar que desde y en el norte «se escribe una literatura que alude irreparablemente al narco. Es imposible huir: el narcotráfico lo avasalla todo y toda escritura sobre el norte es sobre el narcotráfico» (Lemus 2005). Eduardo Antonio Parra responde insistiendo en no etiquetar la literatura del norte como narcoliteratura:

I Martínez G. A., Eduardo Antonio Parra: narrar los instintos, suplemento Confabulario, «El Universal» 28/02/20I5, http://confabulario.eluniversal.com.mx/parra-contar-los-instintos/ (última consulta 20/OI/20I7). 
[...] los escritores del norte hemos señalado que ninguno de nosotros ha abordado el narcotráfico como tema. Si éste asoma en algunas páginas es por que se trata de una situación histórica, es decir, un contexto, no un tema, que envuelve todo el país, aunque se acentúa en ciertas regiones. No se trata, entonces, de una elección, sino de una realidad (Parra 2005).

El narcotráfico es, pues, el contexto desde el que escriben los narradores del norte. Se trata de un fenómeno integral «capaz de cimbrar - no destruir - todos los aspectos de la existencia humana, y también de sacar a relucir todas las miserias» (ibidem). Es aquí donde podemos colocar la narrativa de Eduardo Antonio Parra, en esta región geográfica tan distinta a la del resto del país, donde se habla, se piensa y se siente de modo distinto ${ }^{2}$. En sus cuentos se percibe el fantasma del narcotráfico, se respira la violencia que genera el sistema que lo favorece y lo alimenta. Con pocos y decididos trazos dibuja un escenario de miedo y destrucción, que es a su vez origen y resultado de la criminalidad. Un espacio sin tiempo, sin un antes ni un después, en el que vive la violencia y, al mismo tiempo, un espacio que ya ha sido arrasado por la violencia (González Rodríguez 20I4).

\section{LA NARRATIVA DE LA VIOLENCIA}

En una narrativa que enfrenta los hechos violentos, la de Eduardo Antonio Parra se inserta, pues, en la tradición literaria del norte de México³, que desde principios del siglo XX ha contado con figuras de la talla de Alfonso Reyes, Julio Torri y Martín Luis Guzmán, tres ilustres miembros del Ateneo de la Juventud, de narradores de la Revolución mexicana como Rafael M. Muñoz y Nellie Campobello, de cuentistas del calibre de José Revueltas e Inés Arredondo. Sin embargo, solo a partir de los años ochenta la crítica literaria comienza a hablar de una literatura regional norteña, siguiendo un fenómeno hispanoamericano más amplio que, como señala Alicia Llarena está «en íntima relación con el auge de las periferias en el discurso posmoderno, con la consiguiente descentralización de la cultura, y con las lógicas tensiones

2 «El norte de México no es simple geografía: hay en él un devenir muy distinto al que registra la historia del resto del país; una manera de pensar, de actuar, de sentir y de hablar derivadas de ese mismo devenir y de la lucha constante contra el medio y contra la cultura de los gringos, extraña y absorbente. Derivadas también del rechazo al poder central; de la convivencia con las constantes oleadas de migrantes de los estados del sur y del centro; y de una mitología religiosa "tan lejos de Dios" que se manifiesta en la adoración a santones regionales laicos o más o menos paganos» (Parra 2004: 72), como la Santa de Cabora (Chihuahua), Juan Soldado (Baja California), el Niño Fidencio (Nuevo León) y Malverde (el ‘santo’ de los narcotraficantes sinaloenses). Véase también Parra (200I).

3 Un ejemplo de esta tradición literaria es la reciente antología de cuentos de autores del norte, recopilada y editada por E. A. Parra (2015). 
entre la globalización y el localismo» (2007: I60) . En el caso específico de México, la narrativa del norte de las últimas décadas ha cobrado una fuerza inusitada, tanto por asuntos extraliterarios —difusión editorial—como por el contenido y la indiscutible calidad de la escritura. Dicha calidad se aúna a la dimensión fronteriza y a la reivindicación del paisaje regional.

Precisamente, la caracterización del espacio geográfico en la narrativa de los autores de los años ochenta explica que se les conozca como 'narradores del desierto': Jesús Gardea, Gerardo Cornejo, Ricardo Elizondo, Daniel Sada, Severino Salazar. En la década de los noventa nos encontramos con una nueva promoción, la de los llamados 'narradores del norte' o 'narradores de la frontera', porque añaden a su escritura la presencia cada vez más fuerte de la cultura estadounidense, sobre todo en la zona fronteriza. Dichos narradores presentan, además, ciertas particularidades respecto a otros autores mexicanos: nos ofrecen historias que solo pueden ocurrir en lugares como Tijuana, Culiacán, Monterrey, Mazatlán, o también en el desierto, en la sierra y en la frontera. A esta generación pertenece Eduardo Antonio Parra, junto a Élmer Mendoza, David Toscana, Luis Humberto Crosthwaite, Cristina Rivera Garza, Juan José Rodríguez y Julián Herbert, entre otros. Autores que conforman una narrativa en constante evolución, en búsqueda de nuevas formas de expresión, que se alejan de estructuras lineales para encontrar mayor eficacia en el uso del tiempo (Parra 2004: 76). Una literatura que, aún siendo regional, y por ello periférica desde el punto de vista de la capital del país, en los últimos años ha sido favorecida por una buena difusión editorial no solo nacional ${ }^{4}$.

Si bien Parra ha incursionado en la novela 5 , suele privilegiar el género del cuento con el que se inserta en la tradición literaria mexicana de Juan Rulfo, José Revueltas e Inés Arredondo, demostrando su capacidad de recrear un universo en un solo relato, con la fuerza del inicio y del final que atrapa al lector. De Rulfo toma, sobre todo, la recreación del lenguaje popular, la escritura esencial sin adjetivaciones; de Revueltas, en cambio, el interés por los más pobres y desprotegidos, pero con la diferencia de querer dejar siempre al final de la oscuridad de sus relatos una pequeña, a veces imperceptible, luz de esperanza; con Arredondo comparte la experiencia de incursionar en el interior del ser humano moderno, creando personajes desgarradores a partir de sus límites y sus miserias.

La visión de Parra respecto a la realidad es desencantada, sus personajes suelen tener un destino funesto. La violencia campea en su obra junto a la ternura y la esperanza; la violación va acompañada de la sublimación del

4 A pesar de no quedar claro, como el mismo Parra señala, si la aparente abundancia «representa en realidad un movimiento, o es tan solo una coincidencia cuyo origen se encuentra en el interés comercial de algunas editoriales que decidieron probar suerte con autores y temas novedosos» (Parra 2004: 76).

5 Eduardo Antonio Parra ha escrito hasta hoy dos novelas: Nostalgia de la sombra (2002) y Juárez. El rostro de piedra (2008). 
cuerpo, de los cuerpos. No en vano su narrativa se ha definido como una poética de la violencia, en la que teje pobreza, marginalidad, celos, alcohol, prostitución, muerte. No se trata de un descarnado realismo urbano, ni de un mero retrato desolador de la frontera, sino de la representación literaria de la condición humana, de una crítica social que es testimonio de una realidad dolorosa, violenta, generada y aniquilada por los mismos males. Uno de esos males es el miedo, causa y consecuencia de la violencia que se respira todos los días y a todas horas, porque las violencias difunden sus dominios alimentándose del miedo, del silencio (Reguillo 2000: 76). Así, el miedo en los cuentos de Parra se cuela por doquier, pegándose a la piel de los personajes, provocando una fuerte sensación empática en la que nos reconocemos. Son miedos que en cualquier momento pueden desatar agresión, violencia. Miedos que nos arrinconan, nos roban nuestra condición de seres humanos, y al paralizarnos, nos quitan libertad, posibilidad de acción, como señala el filósofo Carlos Pereda al hablar de «los muchos miedos que provocan los males de la violencia salvaje y que, con frecuencia, aplastan a las personas que somos» (20I2).

El miedo que se transforma en violencia y la violencia que genera miedo, como una única condición que acompaña la vida de los personajes en las tierras del norte, y de la frontera - que es espacio real y simbólico de tránsito y de límite-, serán el hilo conductor del análisis que propongo en este trabajo. La violencia resulta fascinante para Parra, en cuanto coloca al hombre en una situación límite, de frontera, condición que le quita todas las máscaras, le permite sacar a relucir los instintos de sus personajes (Cluff 2003: 224-225). Y lo hace de forma literariamente violenta, a través de un mecanismo de composición que, como veremos, introduce bruscamente elementos extraños que rompen con la lógica narrativa, obteniendo una inesperada grieta por la que se cuela la poesía, el mito, la esperanza que hace soportable la vida.

\section{LOS DESTERRADOS}

Son muchos los cuentos que ha publicado hasta el día de hoy Eduardo Antonio Parra, desde Los límites de la noche (1996) hasta Desterrados (2013) . La abundancia de textos y la limitación del espacio imponen un trabajo de selección finalizado a demostrar que nos encontramos ante una narrativa de ficción que, al ocuparse de personajes marginales, discriminados, invisibles, es testimonio de la cotidiana violación de los derechos humanos que se vive en esa región que recrea el autor, el noreste de México, en territorio

6 La mayoría de los cuentos han sido recopilados en el libro Sombras detrás de la ventana (2009). Se trata de veintiocho cuentos publicados entre I996 y 2006. Otros, más recientes, han sido publicados en el libro Desterrados (2013). El cuento Nadie me hace caso se publicó en Narcocuentos (2014). 
fronterizo. Centro mi atención en Desterrados, el último de sus libros.

¿Quiénes son los desterrados en los cuentos de Parra? Desterrados, sin más, sin artículo, sin adjetivos, para poder declinar el título en los distintos protagonistas de los quince cuentos que se reúnen en este libro. Si desterrado es el «que sufre la pena de destierro», según la definición de la Real Academia Española de la Lengua, el destierro puede ser entendido como castigo, imposición o condena, como tiempo en el que se cumple esta pena, pero también espacio, lugar donde vive el desterrado, «un lugar alejado, remoto o de difícil acceso» como el desierto, como la frontera en los cuentos de Parra. Situaciones de extrema pobreza o de violencia expulsan al sujeto de un territorio determinado o de un lugar simbólico. Condiciones de vida que provocan un destierro, el abandono de la propia casa, el alejamiento de la familia, el dejar el propio país, lo que conlleva una desterritorialización que no es necesariamente geográfica, como la discriminación social, el rechazo, el aislamiento, la invisibilidad.

En los cuentos de Parra el verbo desterrar se conjuga en sus múltiples acepciones, desde echar a alguien de un territorio o lugar directa o indirectamente — por mandato (judicial) o decisión (gubernamental) de quien ejerce el poder-, hasta el expatriarse, apartar de sí (deponer) una realidad, una emoción, una esperanza, un deseo.

El concepto de desterrado implica desterritorialización, en el sentido que le da Pilar Calveiro en Violencias de Estado: en un sistema globalizado donde se desdibujan las fronteras geográficas, sociales y de género (20I2: 2I8), Parra parece deconstruir el discurso bipolar para narrar la realidad actual tratando de entender y dar sentido a lo que sucede hoy. Sus personajes son desterrados que viven o tratan de pasar por ese territorio liminar llamado frontera, definido por él mismo como una segunda especie de limbo.

La nueva hegemonía del sistema neoliberal genera desterrados, a través de un mecanismo en el que los medios de comunicación juegan un papel determinante (Calveiro 20I2: I94) al alimentar una condición que lleva a la inexistencia, a la invisibilidad, al silencio. Asimismo, desde el punto de vista de Sayak Valencia (20I0), los desterrados son producto del capitalismo gore $^{7}$, categoría con la que se hace referencia a la compleja realidad extremadamente violenta de los espacios fronterizos del norte de México, producto del sistema neoliberal, de una economía hegemónica y global.

En este contexto económico, político y social se inserta la escritura de Parra. Su narrativa se define por el espacio, el territorio y la desterritorialización. El ambiente físico orienta inevitablemente su escritura hacia el realismo: privilegia contar lo que sucede respecto a la introspección que se focaliza en la intimidad (Parra 2004: 73). Rompe con el tiempo linear para incursionar en la idea de lo cíclico, del tiempo mítico, donde no hay

7 El término gore proviene de un género cinematográfico que hace referencia a la violencia extrema y tajante. 
fechas ni referencias precisas a situaciones específicas del mundo político o económico. Es el tiempo en el que viven sus personajes, un hoy que se tiñe de pasado en la memoria, y un futuro que se insinúa en los sueños. Así es el tiempo del migrante, del sicario, del vagabundo y del pordiosero, de la prostituta y de la viuda, del exprisionero y del sicario, del exboxeador, de la costurera, del policía, del hombre del desierto, de la frontera, de la ciudad. Todos ellos habitantes del mundo de Desterrados.

Ahora bien, en una escritura caracterizada por el espacio, solo uno de los cuentos de esta colección está ambientado históricamente, El festín de los puercos (Heriberto Frías en Tomóchic,1892), recreación literaria de una masacre que pasó a la historia oficial como triunfo ${ }^{8}$ : la rebelión de cien habitantes del pueblo de Tomóchic aplacada con un ejército de mil doscientos soldados, «una incursión completa destinada a borrar de la tierra y de la memoria de los hombres un pequeño pueblo en un rincón de México que se atrevió a levantarse contra el supremo gobierno» (Parra 2013: 78).

Parra retoma el testimonio indignado del militar Heriberto Frías, Tomochic (1899) $)^{9}$, en un interesante juego de interpretación histórica, con la libertad que permite la creación literaria, para dar su propia versión de lo visto, oído, olido y sentido por el subteniente Heriberto en lo que fue el exterminio del pueblo chihuahuense. El escenario descrito es infernal, las sensaciones transmitidas se intensifican en el uso poético del oxímoron el frío de infierno, en infierno vivo, el silencio que ciega los tímpanos-y en las continuas metáforas que evocan angustia y miedo. Un miedo que, como el frío, paraliza, vuelve sólidas la sombras, sofoca los sonidos; un frío que «se adhiere como escarcha a la angustia» (Parra 20I3: 79); un miedo que duele en el estómago como hoja metálica que papalotea (84). Sin embargo, en la metáfora del hatajo de puercos gordos, hambrientos, salvajes que, como el batallón, deambulan por los escombros y son caníbales, se condensa la crítica histórica al exterminio cruel y bárbaro cometido por los soldados porfirianos:

Todos temen a los puercos más que a los rebeldes. Les tenemos miedo porque somos igual que ellos, piensa el subteniente y ese pensamiento lo llena a un tiempo de vergüenza y satisfacción.

8 Tomóchic es un pueblo de la Sierra Tarahumara, en el estado de Chihuahua, que en la últlima década del siglo XIX contaba con cien habitantes, los mismos que se rebelaron contra medidas injustas y opresivas del gobierno de Porfirio Díaz. Al no lograr aplacar la rebelión, el presidente decidió someterlos enviando un batallón de mil doscientos soldados en octubre de 1892 . Evidentemente, se trató de una masacre cuya crónica fue escrita por Heriberto Frías (I870-I925), subteniente que participó en la acción militar, y se publicó por entregas en el periódico «El Demócrata» de la Ciudad de México con el título ¡Tomóchic! Episodios de campaña. Relación escrita por un testigo presencial. Más tarde aparecerá en forma de novela histórica con el nombre de la población, Tomóchic, texto de denuncia indignada que lo llevaría a la cárcel.

9 Esta novela de Heriberto Frías es uno de los clásicos de la narrativa de la violencia (Parra 2004: 72). 
[...] Nosotros y los generales y los caciques y la Iglesia y los extranjeros dueños de las minas y el presidente Díaz. Somos puercos que devoramos el cadáver de este pobre pueblo después de verlo defenderse hasta morir. No soportamos a los héroes. Nos dan miedo. Hay que borrarlos de la memoria de los hombres (82).

Crítica histórica y representación de la condición humana en sus límites más abyectos, expresada en la analogía entre los hombres y los puercos que, «como nosotros los humanos, devoran todo lo que tienen enfrente, incluso a ellos mismos» (ibidem). El destierro definitivo de los tomoches va de la mano del destierro de los soldados de su condición de hombres. En medio de este escenario desolador y angustiante, una luz de esperanza se enciende en el reconocimiento a la memoria, al valor del testimonio, que llevará a Heriberto Frías a dejar la espada y tomar la pluma para escribir un poema épico que recuerde la matanza y evite el olvido (85), un texto que le valdrá la cárcel.

Los demás cuentos, como señalaba, no tienen referencia temporal alguna —solo el tiempo implícito en la memoria y en los sueños-, están caracterizados por el espacio liminar, fronterizo, móvil.

\section{LA FRONTERA}

La frontera es el espacio del migrante y también del desplazado. Lugar de desterrados. Así lo representa Parra desde el primer cuento de la colección objeto de estudio. Relato narrado en primera persona: la voz de El caminante se mueve en un flujo de conciencia en el que tiempo y espacio parecen girar sin dirección alguna, en el andar continuo del migrante perdido en sus recuerdos y sus sueños.

El inicio coloca inmediatamente al lector en ese devenir constante que es el camino, dando la sensación de acompañarlo por un tramo, el del relato. En las primeras líneas se concentra la información esencial que permite saber que se trata de un hijo único, de familia campesina, que deja su pueblo cuando la madre muere para ir a buscar las huellas del padre, «apenas entrevisto en los primeros pliegues de la niñez, desaparecido allende la frontera, como se esfuman las nubes tras las montañas: por el empuje del viento» (Parra 2013: II).

Dos tópicos se enhebran: la frontera y la búsqueda del padre, representados como sueño que se transforma en pesadilla, como deseo que se confunde con el propio destino. El motor que casi como fuerza ajena mueve y empuja a emprender el camino es la búsqueda del padre; para encontrarlo tiene que atravesar la frontera, una frontera de cuya existencia no está se- 
guro, en una confusión de recuerdos y sueños construidos a través del relato del otro: de su madre, del viejo sabio del pueblo que la conocía y el de los transeúntes que como él se dirigen hacia la misma meta. «¿Existirá ese lugar al que algunos llaman frontera?» (ibidem). Una pregunta que revela el violento contraste entre el sueño de riqueza que aguarda al otro lado del río y la pobreza, los andrajos, la expresión hambrienta de los migrantes.

La imagen de Estados Unidos, construida por la voz de la madre, es «una nación de hábitos raros, ciudades de oro y dioses crueles, cuya lengua resulta incomprensible», de un reino «protegido por muros y ríos anchísimos, con un ejército diestro en impedir la invasión de los bárbaros de piel oscura». A pesar de todo ello, «desde tiempos antiguos» muchos de esos bárbaros -ellos, su padre y él, los mexicanos — «traspasan el límite con el fin de perderse en las ciudades áureas del país ajeno» (I2). Un lugar de tintas míticas que sigue atrayendo como imán con el sueño dorado, pero que lleva inevitablemente a la confusión, a la pérdida de identidad y de raíces en un territorio ajeno. Cruzar el río — símbolo de la frontera-implica, entonces, dejarse detrás la propia historia, perder la memoria, y por ello el caminante no encuentra en su interior las referencias suficientes para saber quién es y de dónde viene. Confundido, vive sin tiempo, en el pasado de sus recuerdos y en el futuro de sus sueños, «vivía en el pasado y el futuro a la vez» (I3), «siempre en el camino, en medio de ninguna parte» (II), en un espacio en el que se mueve como en un círculo, sin alejarse del origen y sin acercarse a la meta. El caminante se pierde a sí mismo sin haber llegado, con un pasado a cuestas que se deslava, se borra y sus sueños se vuelven pesadillas. El camino que debería llevar a la realización del sueño se va transformando en sufrimiento. Por ello pocos emprenden el camino y muchos se quedan simplemente mirándolo. Es el camino la existencia misma, un ser vivo, infinito y violento, un dios iracundo y caprichoso de cuyas garras el migrante se salva solo con la violencia de la muerte. El impulso a abandonarlo es fuerte, el caminante se da cuenta de que todo es una ilusión, una falsedad. El sol lleno de odio lo quema, lo enceguece. Los pocos campesinos que encuentra le niegan el pan, la sed le seca hasta los ojos y le impide ver. Solo esos recuerdos que retiene en sueños lo animan a seguir caminando. La memoria resulta ser el único punto de referencia posible para quien emprende el camino, el motor que permite dar los pasos, único eje estructurador que evita el desmoronamiento, la pérdida total. Y, sin embargo, el pasado impide caminar hacia adelante: «Ahora lo sé: cuando alcance la orilla opuesta, sin nada que me retenga en el pasado, encontraré sin problema el siguiente tramo del camino» (I6).

El río, esa frontera hecha de aguas violentas, con dimensiones de lago o de laguna con aspecto de mar, es parte del camino mismo. Ese río que parece multiplicarse. Cada vez que el caminante cruza el límite que marca el río se aturde, se marea, confunde los recuerdos con los sueños, siente que va 
perdiendo la memoria y acaba por reinventar su historia, en la que conviven en lucha continua la necesidad y el deseo, la constricción y el sueño, el dolor junto a la esperanza. Ese límite es la frontera, esa especie de limbo donde los orígenes se ven un poco desdibujados (Cluff 2003: 219) se vive como ilusión, esperanza vana, embuste, «un cuento que las madres han inventado con objeto de explicar a los hijos la ausencia de los padres» (Parra 2013: 13). Una explicación que llevará a nuestro Telémaco del norte árido y desamparado de México a dejar la casa, el pueblo, el abrazo acogedor de una mujer, la memoria feliz de los primeros años «para seguir las pisadas del autor de mis días» (II).

Manteniéndonos en el ámbito de lo liminar y fronterizo, el camino del migrante se transforma en carretera que divide dos mundos en el cuento En la orilla. La voz sin nombre - como en el relato anterior- de un habitante del llano desértico se transforma en el grito silencioso de la invisibilidad. Un espacio de miseria, sequía, desolación e inmovilidad, y una línea, una carretera por la que transita el otro mundo de automóviles, de riqueza, de gente limpia y elegante que nunca lo ve.

$\mathrm{Al}$ igual que en El caminante, la desorientación acompaña a quien mira hacia el otro lado, hacia la frontera, cilusión o necesidad?, «porque quién sabe si de verdad del otro lado haya algo diferente a esto, y al final queda dando vueltas en redondo, unos pasos por aquí, otro por allá, pa acabar siempre donde mismo» (34). Parra coloca al lector ante un doble contraste que pasa por los ojos: el desterrado del desierto que en la orilla, es decir, en el límite —geográfico, social, económico- donde el sistema lo ha colocado, mira transitar sus sueños como coches que de vez en cuando pasan por ese lugar:

[...] porque a lo mejor nos conformaríamos con que nos vieran, nomás con eso, nos daría algo de contento que al transitar por aquí por donde está la poquita gente que vaga en el desierto detuvieran aunque fuera una nada su loca carrera hacia donde van y giraran a medias la cabeza pa plantar en alguno la vista, sí, la vista, porque una sonrisa o un saludo sabemos que sería mucho pedir, nomás una mirada, aunque fuera rápida, un brillo en las niñas de los ojos que nos hicieran sentir que de veras estamos aquí, que de veras existimos y no somos las ánimas sin vida que en veces creemos ser y que es como nos vemos entre nosotros (33).

El deseo de ser visto y la frustración de ser inexistente e invisible para ese otro mundo que lo ignora desemboca inesperadamente en un gesto mortal. Será un cascote de cemento desprendido de un inútil cuanto absurdo puente, construido años antes como parte del contradictorio discurso oficial 
de la modernidad para evitar el peligro de cruzar por una carretera por la que al máximo pasan tres coches al día y que servirá solo a dar sombra a los que desde allí ven sin ser vistos, el instrumento con el que bruscamente se rompe la inmovilidad enceguecedora en la que se desarrolla el relato para desencadenar el trágico final: «esta vez, segurísimo estoy, sí plantó las niñas de sus ojos en mí pa verme muy bien cuando alcé la piedra por encima de mi cabeza, antes de dar el volantazo que hizo chirriar las llantas con un ruido fuerte» (4I).

Con la misma violencia inesperada con que lanza el cascote el protagonista del cuento, Parra coloca al lector ante la perspectiva real del tú, destinatario de la narración: «aunque nunca se me ocurrió que en la máquina viniera usted, una mujer, una hembra como muchas de las que pasan por aquí» (ibidem). Dicha perspectiva refuerza la idea de denuncia desde el lugar del enunciado; sin mayúsculas, sin cortes de puntos e insertando continuamente puntos suspensivos, la narración marca el ritmo lento y el tono llano y susurrado del habitante del desierto, que reclama la indiferencia: «... jamás les hemos importado» (32), «... pero pa qué contar todo esto, ¿no?, si a ustedes no les importamos, nunca les hemos importado ni les importaremos, será nomás pa llenar el silencio de palabras, con eso de que este lugar es tan callado...» (36). Es evidente, pues, el menosprecio y la ignorancia que pesa sobre ellos, representantes del llamado Tercer Mundo, que nos lleva a ver los elementos y dinámicas ajenos al capitalismo dominante como insignificantes, «y ahora, ese descuido y menosprecio, desde el silencio y la invisibilidad, ha ido fraguando una respuesta que parece indetenible e irreconociblemente violenta» (Valencia 2OIO: 2I).

\section{LA CIUDAD}

Deambulan en estos cuentos otros desterrados, los de la ciudad, ese espacio urbano donde junto al aire contaminado se respira el miedo, donde el destierro, generado por la globalización y su modernidad, cobra distintas expresiones.

Así, desde el mostrador de la tienda del barrio la voz del tendero cuenta el Último round del Campeón, probable exboxeador, extraño y rudo, quien en su lucha constante por defender su derecho «a pasear sus pies descalzos por la calle» (Parra 20I3: 57) discutía de todo y con todos y con facilidad acababa dando golpes. Sin embargo, los vecinos lo aceptaban e incluso lo protegían de la policía cuando sus reacciones se habían vuelto desmedidas y peligrosas a raíz de la construcción de una avenida que rebanó la manzana donde vivía: «Cosas del progreso. Ya se sabe: la ciudad crece» (ibidem). El Campeón, entonces, decidido a defenderse de la violencia del progreso a su manera, regaba basura en la avenida, lanzaba piedras a los coches, insultaba 
a gritos a los conductores, hacía señas obscenas hasta que, bajo los efectos del calor y de la exasperación, llegó ese inesperado «último round» con el que finalmente el Campeón derrotó al enemigo, detuvo la carrera sin fin de un coche dándole fuego.

Los rápidos y drásticos avances del progreso que trae consigo la globalización impedirán la reintegración en la sociedad de quien sale de la cárcel después de haber descontado su pena. Así sucede con El hombre del costal, quien carga simbólicamente con un pasado, mientras deambula sin rumbo por las calles de una ciudad que no reconoce. Lo miran diariamente desde un restaurante al que suele entrar sin mirar a nadie, buscando algo aparentemente indefinido y sembrando desconcierto. La narración, sin pausas, es un flujo que forma un párrafo único en el que se cruzan dos puntos de vista: el de quien observándolo lo describe y el suyo propio. La voz del hombre del costal de lona se inserta así en la narración externa para decir su sentir, su miedo, la paradoja de su destierro: al haberse liberado del encierro de la prisión —espacio liminar-, se descubre prisionero de su pasado y de una realidad que le es ajena y, por tanto, es incapaz de interpretar:

[...] no hay nada, puro hueco, pura oscuridad, ¿iverdad que no se vale?, pos así me sentí yo al salir cuando ya nomás ni la vieja ni los cuates estaban, tampoco la colonia, y si le busco un poquito más tampoco la ciudad: nada es lo mismo, compadre, ya no sé ni lo que ven mis ojos... (6I)

El destierro de la prisión lo dejó fuera de un mundo en continuo cambio y en el que la cultura norteamericana iba ocupando cada vez mayor espacio: «¿a qué hora nos conquistaron los gabachos que nadie se dignó avisarme?» (64). Al salir de la cárcel, la imposibilidad de entender lo que se le presenta ante sus ojos, junto a su condición de exreo — ese 'otro' diferente que «provocaba mucha lástima [...] y también miedo» (62) —, acaban no solo por mantenerlo en su condición de desterrado, pues su creciente desesperación y desasosiego lo llevarán, en un gesto tan violento y desconcertante como la ciudad que encontró al terminar su condena, al encierro y al destierro del único mundo que conoce.

Al igual que El hombre del costal, el protagonista de Nadie provoca miedo, lástima, y también asco. En continuo movimiento, andrajoso y apestoso, conocido con el apodo de el Vikingo, este personaje camina por las calles de la ciudad empujando un carrito del supermercado con sus pocas pertenencias. Así lo describe un narrador en tercera persona que relata la triste historia de un hombre despojado de su dignidad, de su identidad, su memoria y su humanidad en las múltiples torturas padecidas en los separos de la policía. «No soy nadie. No vi nada», «No soy nadie. Tampoco oí nada», «No soy nadie. Ni nombre tengo», recita la letanía repetida incesantemente por 
el Vikingo como un mantra salvífico que se introduce con la insistencia de la sobrevivencia en la narración.

Estamos, una vez más, ante un sujeto paralizado por el miedo, el que le han provocado y el que infunde a su vez, como en un círculo sin principio ni fin. El Vikingo ha sido víctima de la violencia de la fuerza pública, un poder que omite cualquier posibilidad de defensa, ante acusaciones falsas de delitos ajenos por los que tiene que pagar, y como una pesadilla la escena se repite, y como en una trampa lo condenan a caer en manos de sus mismos acusadores y torturadores. Vuelve el tiempo circular en el que lo que fue, lo que será, lo que es, lo que puede ser y lo que desearíamos que fuese se mezclan de la misma manera que en otros cuentos de Parra.

\begin{abstract}
No sé nada, mi jefe. Nunca veo nada. No soy nadie. [...] Piensa que su historia se repite, que de ahí lo llevarán a los separos de la delegación o a cualquier sótano para sacarle la verdad, que van a querer cargarle un muerto al que ni conocía, como ya lo han hecho otras veces, y que después de unas semanas o un par de años en el penal lo volverán a echar a la calle donde tendrá que buscar un portón y un carrito de súper para seguir caminando (I4I).
\end{abstract}

La corrupción de las fuerzas del orden acaban destruyendo física y moralmente al hombre. Lo aniquilan. Víctima de una condición sociopolítica en la cual la complicidad habitual entre poderes —estatal y criminal - es habitual (Domínguez Ruvalcaba 20I5), lo transforman en un deshecho de la sociedad; se alimenta de lo que sobra, de lo que los vecinos tiran en los basureros. Y como desecho es percibido: «Algunas con asco, otras con temor, todas las miradas se desvían al toparse con su enorme figura cubierta de pantalones de varios colores, camisetas, sudaderas, suéter, saco y un abrigo claro lleno de lamparones que arrastra por el suelo» (I32).

En otros casos, la ciudad puede representar un refugio para quien busca el anonimato entre las multitudes, para quien se esconde convencido de que en medio de veinte millones de hombres y mujeres no lo localizarán. Un lugar donde ser nadie es un deseo; o acaso ser un ciudadano más, «alguien que no debía ni temía nada, alguien a quien ningún matón vendría a ejecutar» (IOI). Para Bernabé Romero en Un diente sobre el pavimento, Ciudad de México, esa «urbe monstruosa», resultaba ser el lugar más seguro del mundo, «una suerte de remanso de paz casi inconcebible» (I03), después de una fuga de meses de pueblo en pueblo, de rancho en rancho, entre el desierto y la sierra. Del norte al centro, del desierto a la ciudad, huye perseguido por todos al haber dejado su oficio - sicario al servicio de la comandancia judicial—, ya cansado de obedecer, sin ganancias y sin un instante de tranquilidad. Vive huyendo con el miedo en el cuerpo, un miedo que se vuelve paranoia — «todo está dentro de mí» (IO4)—, que altera la percepción de la 
realidad.

Si la ciudad le da la libertad de movimiento, perdiéndose entre rostros desconocidos y por ello inofensivos (I03), es en el metro donde se siente más seguro, en medio de esa multitud amasada, en ese vagón cerrado donde no cabía un cuerpo más y viajan todos encimados. Sin embargo, es precisamente ahí donde siente de repente el lenguaje preciso de su cuerpo, en el que confía sin reserva porque sus instintos siempre habían respondido mejor que sus pensamientos. Y ahora su cuerpo se tensiona, las manos le sudan, la nuca punza, señales de peligro inminente que no sabe interpretar en ese ámbito diverso que es la ciudad. Además, se encuentra en un espacio cerrado y limitado donde los cuerpos necesariamente se tocan, se rozan, se enciman, se mueven y se amontonan rompiendo la frontera que los separa, creando confusión. Entre los ruidos, las voces y humores húmedos del vagón intenta «rastrear el aroma de la piel asoleada, de carne mucho tiempo a la intemperie, que debía despedir quien vinera en su busca. No percibió nada y, no obstante, la presión en su cráneo se había vuelto tan concreta como si tuviera el cañón de un arma pegado a él» (98).

Entonces se dio cuenta de que la capital ya no era para él un refugio (103). En alerta continua, con el miedo dentro, estudia los cuerpos de quienes lo rodean en el vagón y en el andén sin poder identificar el peligro entre esos desconocidos, oficinistas, albañiles, secretarias y señoras gordas. No podrá entonces evitarlo, solo presentirlo. Huye y es perseguido. Dos sujetos lo agreden precisamente en la calle donde habían filmado una de sus películas favoritas de la infancia y, al reconocerla con emoción después de la golpiza, saca al lector bruscamente del clima de miedo que había acompañado el relato. Y así, un diente sobre el pavimento tirado en ese callejón del centro histórico de Ciudad de México, metonimia de un cuerpo golpeado, inesperadamente se transformará en signo de alivio estremecedor, de liberación del miedo contenido en el cuerpo de Bernabé: «Se trataba de un golpe; fuerte y doloroso, sí, pero nomás un golpe» (ıо6).

\section{El CUerpo}

Algunos de los cuentos de Desterrados son la representación desgarradora de los cuerpos concebidos como productos de intercambio, mercancía encarnada literalmente por el cuerpo y la vida humana a través de técnicas de violencia extrema aplicada en el espacio fronterizo (Valencia 20I0: I5).

El cuerpo de una niña casi adolescente, el cuerpo inmóvil de un niño de mirada triste, el cuerpo de una mujer decadente, madre y prostituta, el cuerpo de un hombre abusador disfrazado de Santa Claus transitan en El despertar de la calle antes del amanecer de una Navidad entre pobres. Cuerpos objeto, cuerpos dolientes, cuerpos abusados y maltratados, cuerpo violenta- 
do. La niña con cuerpo aún infantil y aspecto de adulto trata de proteger a su hermano. A él se dirige con su nombre, Joaquín; le cuenta, lo acaricia, le explica con ternura que el señor vestido de rojo no le llevara regalos porque, como decía su abuela, era pura invención de los gringos, un engaño. Mejor esperar a los Reyes... y con ellos parece querer esperar, quizás, días mejores, sin frío y sin hambre.

La violencia del abandono, de la prostitución y el abuso de menores se va desvelando en el relato de la niña que descubre gradualmente que detrás del disfraz, del peluche, de la barba y del traje rojo del personaje bueno de Navidad existe un hombre malo, falso y borracho: sin el disfraz, sin las barbas «volvió a ser otro borracho de la colonia, uno de los que me dicen cosas cochinas si me ven venir» (Parra 20I3: III). Alcohol, sexo, golpes, humillación es lo que ve en la relación de su madre con ese hombre: «Afuera siguieron pegándose y jaloneándose. Y todo terminó cuando ella le estrelló al viejo una y otra vez la botella en la cabeza hasta que se reventó y brincaron vidrios por todas partes. Cayó en el lodo. [...] Después se fue corriendo, asustada porque el viejo no se movía» (IIo).

En un escenario de marginación y degrado dos niños solos, desde que su abuela murió, viven continuamente abandonados por 'ella', su madre. Hiere la distancia y la frialdad representadas en el uso de esa tercera persona como único modo de nombrarla, ahonda la ruptura, niega el vínculo. Ella los abandona y la niña la destierra de su corazón, de su vida. Las fotografías de 'ella' eran lo último que quedaba que pudiera arder en esa cubeta de lámina con la que se calentaban. Las quema, una por una, en un gesto inconscientemente simbólico que desembocará en un algo tan sencillo como abrir la puerta «dejando entrar al cuarto un chorro de luz acompañado por el aire frío y una gritería divertida» (III).

El cuerpo enigmático y ambiguo del personaje de La costurera es descrito en la voz de una chico adolescente que descubre una identidad sexual oculta. Figura clave en su infancia vivida en el mundo exclusivamente femenino de su madre y su abuela, quienes lo trataban como la niña que hubieran querido que fuese. No obstante su condición de elemento extraño al núcleo familiar, acaba siendo la persona más cercana, a quien debe todo lo que es (55). Un cuento que se construye a partir de la ambigüedad de las fronteras de género: la costurera es necesariamente mujer para ejercer su oficio, para trabajar con una familia y ser merecedora de la confianza que le permite ocuparse del niño y atender a las clientes del taller.

El cuerpo marca el límite de género. El cuerpo del niño, el cuerpo de La costurera, los cuerpos de las clientas. El cuerpo del niño, que su madre y su abuela visten como si de una niña se tratara, con su melena larga y sus vestidos color de rosa, el mismo cuerpo que la costurera va moldeando cosiéndole pantalones, cortándole el pelo, siguiendo un conocido patrón masculino. Ese cuerpo, de aspecto rudo, feo, porque es «ancha de espaldas, 
velluda, hombruna» (43), anula cualquier elemento de rivalidad femenina y cualquier sospecha que ponga en entredicho el trato con el cuerpo de las clientas que toca cada vez que tiene que medir y probar prendas. Cuerpos que a su vez la costurera muestra al adolescente como parte de esa misión paterna de hacerlo hombre y que se va desvelando desde la primera línea del relato: «Acostúmbrate desde ahora a ser hombre» (42).

La inquietud que en ciertos momentos generan los gestos corporales de la costurera en el chico se esfuma ante su actitud, sus atinados consejos, sus palabras, sus regalos. Ambigüedad que se intuye a través de numerosos detalles, desde los nombres que se invierten en el juego de la doble identidad, María José/José María, hasta los gestos precisos y complicidades cuando de mujeres se trata. El final se desvela no como algo inesperado, sino como descubrimiento dramático del secreto de un hombre, padre de familia, que se ve obligado a enmascarar la propia identidad para poder acceder a un trabajo en una sociedad machista que destierra al diferente, lo discrimina y lo margina.

Los hombres han de hacer cosas de hombres, carpintería, soldadura; o ser doctores o abogados. Pero hay señores que cosen, acuérdate de Chuy Juárez. Ay, René... Chuy Juárez es rarito, ¿no ves cómo levanta burlas en la calle? Fíjate en sus caminados, en la ropa que usa, y en su greña igual a la que traías de chiquito y yo te corté. Tú no quieres ser así. ¿Te gustaría que te dijeran "mariquita"? De pronto visualicé al otro modisto de la ciudad contoneándose por la plaza, hablando con su voz de flauta y mirando ilusionado a los muchachos. No, dije. Yo soy hombre (49).

Nuevamente el autor cierra la narración dejando una chispa de esperanza, al devolver a María José su identidad de José María a los ojos del adolescente, quien de lejos, y mirándolo en su contexto familiar, reconoce «sus manos grandes de dedos delgados, como para realizar trabajos manuales finos, la panza que sobresalía de su cuerpo más bien delgado, las canas en las sienes y la sombra clara del bigote sobre el labio superior» (56), el ademán de la caricia en la cabeza de sus hijos que tan bien conocía, para luego encontrar su propia mirada, que desde allí le brindaba un guiño de complicidad iluminado por una franca sonrisa.

La represión del cuerpo en Calor callado está representada por la resignación de una mujer soltera, obligada por la sociedad machista a callar sus instintos, sus deseos. Los maullidos de una gata en celo, en una noche de calor sofocante, no solo le impiden dormir a Tania, sino que, en una hábil cuanto sugerente analogía — «Ambas estaban dispuestas a entregarse, hacían lo posible por llamar la atención de los machos, pero algo semejante al miedo las mantenía lejos de ellos» (I25)—, despiertan sus propios apetitos y 
fantasías sexuales. La lucha entre el deseo y el miedo las paraliza, el instinto de autoprotección las aleja del deseo cargado de peligro. Mientras Tania, en la intimidad de su cuarto, juega con la imaginación y las ganas contenidas y acalladas, su hermano sale libremente a satisfacer los suyos. «Aristeo había comprendido que le sería imposible dormir y se iba a la calle. El muy cabrón, pensó Tania [...]. Para él es fácil. Nomás va a uno de sus antros y de ahí al hotel, o se trae su ligue aquí, cuando no tiene dinero» (I24).

El cuerpo en Paréntesis juega peligrosamente con la sensualidad al límite de lo permitido. Una pareja de desconocidos, que por casualidad se encuentran cenando juntos en un restaurante, entran poco a poco en una dimensión de puro deseo sexual exento de contención sin tocarse. «Apenas se sentaron, uno junto al otro, la atmósfera de intimidad que los envolvía hizo que Mariano experimentara la sensación de estar cometiendo un acto prohibido» (87), y con esa sensación inicia un juego de miradas, suposiciones, alusiones que van aumentando hasta el límite marcado por una evidencia: «simplemente somos adultos, ¿no? Sí, adultos... casados» (89). Existía una frontera que separaba, contenía e imponía límites a los cuerpos pero no a la fuerza de la imaginación, del deseo intenso alimentado por las palabras que «eran roces, caricias, besos que tras penetrarle los tímpanos recorrían los rincones de su cuerpo cada vez con mayor confianza» (9I). Caricias ocultas y audaces que los llevan a una relación sexual sin contacto corporal, acompañada de los sudores, los suspiros, la tensión, la excitación, el estremecimiento, la erección. El timbre del celular de Lucrecia los volvió violentamente a la realidad y en pocos minutos estaba cada uno en otro lugar.

La presencia del cuerpo muerto, frontera entre la vida y la muerte, es elemento narrativo de dos cuentos. En espera de que llegue La madre del difunto, Lauro, policía de un pueblo del norte, cuida el cadáver en fase de putrefacción de ese desconocido que por banales motivos murió ahí, «en su cerebro sólo hay espacio para el cuerpo que, a pesar del hielo, se pudre sin remedio al fondo del pasillo» (I42). La espera, entonces, da lugar a la recuperación de la memoria, a la reconstrucción de la muerte de la propia madre. Se da cuenta de que «la nueva página es igual a la anterior» (I44), y las coincidencias lo demuestran: desde el tiempo de espera, en su caso necesario para regresar de Estados Unidos, hasta el calor de ese pueblo que descompone los cuerpos, atrayendo moscas y despidiendo mal olor. En medio de una intensa sensación de asco, irrumpe lo poético con la fuerza de la memoria y la reconciliación. La lectura de una larga carta que encuentra casualmente en el escritorio de su jefe, en la que un hombre - ¿el difunto? - relata los años recientes de su vida comparándolos con un largo deambular en un desierto, en un mundo incomprensible, carente de afectos, sin esperanza y sin posibilidad de comunicación. «Ningún lugar es mejor que otro: todos son ajenos, oscuros, fríos» (I52). Y, sobre todo, reconoce en la madre, destinataria de sus palabras, el único aliento que le queda: le pide 
perdón por permanecer lejos y espera volver a verla. Lauro se emociona profundamente leyendo una historia semejante a la suya, ignora el violento hedor de la celda y, en un gesto de agradecimiento, se pone a limpiar el rostro y las manos del cadáver en evidente estado de descomposición, «le acomoda saco y pantalón al muerto con el fin de que su aspecto sea menos desagradable» para que su madre no lo vea en esas condiciones (I54). Se conmueve al conocer a la madre que llega a identificar y retirar el cadáver del hijo, siente que ya la conoce, que es como la describe la carta. Sin embargo, en el momento final en que quiere entregarle la carta a Aníbal, descubre lo que nunca hubiera imaginado, que en realidad el autor de la carta es precisamente él, su jefe.

En Mal día para un velorio el marido y la madre de la difunta Lorena, amantes desde hace cuatro años, terminan haciendo el amor junto al ataúd de la esposa/hija, donde yace un cuerpo muerto que ha dejado de ser lo que era: «Esto ya no es mi hija» (3I), dice la madre; «Nada de Lorena quedaba en ese bulto de carne yerta que en cuestión de horas empezaría a descomponerse» (29), dice el viudo, que en una mezcla de arrepentimiento y dolor le pide perdón por la traición. La violencia de la vida irrumpe al lado de la muerte en la atracción sexual sin límites que viven los parientes más cercanos de la muerta: su marido y su madre. Un juego erótico avasallador encierra a los amantes en su propio mundo, desterrando otras emociones.

De nuevo el cuerpo sin vida, esta a vez en el recuerdo evocado por una muerte reciente, se manifiesta en Nunca había oído la letra. La viuda entra en una cantina, espacio exclusivamente masculino, movida por el dolor y la tristeza. Rompe reglas, se aventura en un espacio desconocido que la excluye y la rechaza con tal de escuchar la canción que su marido, recién fallecido, siempre silbaba y hubiera querido escuchar en el último instante, pero como no se la sabía, no pudo satisfacer su último deseo. Finalmente, alguien la pone en la sinfonola, ella la reconoce con emoción, y al escuchar la letra, que nunca había oído, entiende lo que por mucho tiempo intentó decirle su marido (75). Si no en vida, en el cementerio podrá cumplir, paradójicamente, ese deseo llevando un trío para que le cante al difunto «Si me dejas ahora».

Espacio de la memoria, el cuerpo en estos cuentos es lenguaje de emociones, lugar de sentimientos en el que nacen y se manifiestan los límites, los instintos en su profunda humanidad. El cuerpo es víctima de la violencia y por ello testimonio tangible del dolor, del abuso, de la agresión, pero también del deseo, el anhelo y los sueños.

Como hemos visto a lo largo de estas páginas, no siempre los personajes de los cuentos tienen nombre propio. Parra suele utilizar el apodo o el adjetivo que lo califica como si se tratara de una carta de la lotería de los desterrados: el caminante, el campeón, el vikingo, el hombre del costal, la costurera, el invisible, la niña, la viuda, los amantes. Habitantes de un espacio donde el miedo enloquece, confunde, paraliza, trastocando la percepción del tiempo. 
Protagonistas del propio drama cotidiano, forman parte y son resultado de un sistema criminal en el que es casi imposible separar los poderes que lo conforman.

La recreación literaria de la condición humana, en sus emociones e instintos, hace universal lo que nace come realidad local, geográficamente delimitada. Un mundo donde los cuerpos reemplazan la mercancía, y como tal se trafica con ellos, se dispone de ellos. Un mundo donde es difícil hablar de lo que hace enmudecer, porque la violencia extrema y espectacular no solo atenta contra la vida humana, sino contra la condición humana (Cavarero 2009). La crítica social sin miramientos Parra la hace a través del concepto de límite, como frontera y como condición extrema en la que el sistema coloca al ser humano. Lo hace con el recurso imprescindible del lenguaje, contraponiendo al horror el lenguaje del dolor, único posible cuando los hechos rebasan nuestra capacidad de entendimiento.

Considero que la narrativa de la violencia de Eduardo Antonio Parra responde afirmativamente a la cuestión sobre la posibilidad de una poética en medio de la violencia descarnada, ya planteada en el siglo XX por filósofos y poetas como Hanna Arendt, Paul Celan, Primo Levi, Walter Benjamin, Jan Assman. La fuerza de la palabra se introduce en el planteamiento formulado por Cristina Rivera Garza en Los muertos indóciles sobre la producción de valor social a través de la escritura: «En plena era del semiocapitalismo, ¿pueden los escritores imaginar y producir una práctica lingüística capaz de generar un mundo alternativo a la dominación del capital?» (2013: 44). Los cuentos que en este trabajo se han presentado representan un testimonio concreto de la palabra poética como resistencia, como posibilidad de sobrevivir al 'horrorismo', soportar el miedo, imaginar otros mundos posibles, incluso cuando la violencia es parte intrínseca de la escritura. La narrativa de Parra demuestra, una vez más, la capacidad única del hombre de contradecir y desdecir el mundo, de imaginarlo y hablarlo de otro modo (Steiner 2007).

\section{Bibliografía}

Calverio P., 20I2, Violencias de Estado. La guerra antiterrorista y la guerra contra el crimen como medios de control global, México, Siglo XXI.

Cavarero A., 2009, Horrorismo. Nombrando la violencia contemporánea, México/ Barcelona, Universidad Metropolitana de México/Antrophos.

Cluff R., 2003, Eduardo Antonio Parra y la zona intermedia (ensayo y entrevista), 
en A. Pavón (ed.), Púshale un cuento al piano (La ficción en México), México, Universidad Autónoma de Tlaxcala/Conaculta.

Domínguez Ruvalcaba H., 2015, Nación criminal, México, Ariel.

Frías H., 2002, Tomóchic, México, Océano, (1899).

González Rodríguez S., 20I4, Campo de guerra, Barcelona, Anagrama.

Lemus R., 2005, Balas de Salva, «Letras Libres» 30/09/2005, http://www. letraslibres.com/mexico/balas-salva (última consulta: 26/0I/20I7).

Llarena A., 2004, Espacio e identidad: narradores del norte de México, «ConNotas. Revista de crítica y teoría literarias» 2/3: I93-2I3.

-, 2007, Espacio, identidad y literatura en Hispanoamérica, Culiacán, Universidad Autónoma de Sinaloa.

Parra E. A., I996, Los límites de la noche, México, Ediciones Era.

200I, Notas sobre la nueva narrativa del norte, «La Jornada Semanal»27/05/200I, http://www.jornada.unam.mx/200I/05/27/sem-parra.htm (última consulta: 26/0I/20I7).

-, 2002, Nostalgia de la sombra, México, Tusquets Editores.

—, 2004, El lenguaje de la narrativa del norte de México, «Revista de Crítica Literaria Latinoamericana» 30/59: 7I-77.

—, 2005, Norte, narcotráfico y literatura, «Letras Libres» 31/10/2005, http://www. letraslibres.com/mexico/norte-narcotrafico-y-literatura (última consulta: 26/0I/20I7).

—, 2008, Juárez. El rostro de piedra, México, Grijalbo.

-, 2009, Sombras detrás de la ventana, México, Ediciones Era/Conaculta/Fondo Editorial de Nuevo León/Universidad Autónoma de Nuevo León.

—, 2013, Desterrados, México, Ediciones Era/Universidad Autónoma de Nuevo León/Universidad Autónoma de Sinaloa.

—, 20I4, Nadie me hace caso, en Aa. Vv., Narcocuentos, México, Ediciones B: I57-I77.

- (comp.), 20I5, Norte. Una antología de cuentos, México, Ediciones Era/Conaculta/ Fondo Editorial de Nuevo León/Universidad Autónoma de Sinaloa/Conarte/ UAS.

Pereda C., 20I2, Los males del mal, «Nexos» OI/02/20I2, http://www.nexos.com. $\mathrm{mx} /$ ?p=I4676 (última consulta: 26/OI/20I7).

Reguillo R., 2000, Identidades culturales y espacio público. Un mapa de los silencios, «Diálogos de la comunicación» 59/60: 75-86, http://www.narrativas.com.ar/ Apuntes/Reguillo\%2oMapa.pdf (última consulta: 26/0I/20I7).

Rivera Garza C., 20I3, Los muertos indóciles. Necroescrituras y desapropiación, México, Tusquets.

Rodríguez Lozano M., 2002, El norte: una experiencia contemporánea en la narrativa mexicana, Monterrey, Fondo Estatal para la Cultura y las Artes de Nuevo León.

Steiner G., 2007, Presencias reales, Barcelona, Destino.

Valencia S., 2010, Capitalismo gore, Barcelona, Melusina. 
